\title{
Response of a zonal climate-ice sheet model to the orbital perturbations during the Quaternary ice ages ${ }^{1}$
}

\author{
By DAVID POLLARD and ANDREW P. INGERSOLL, Division of Geological and Planetary \\ Sciences, California Institute of Technology, Pasadena, California 91125, U.S.A. \\ and JOHN G. LOCKWOOD, School of Geography, University of Leeds, Leeds LS2 9JT, England
}

(Manuscript received October 24 1979; in final form January 8, 1980)

\begin{abstract}
The astronomical theory of the ice ages is investigated using a simple climate model which includes the ice sheets explicitly. A one-level, zonally averaged, seasonal energy-balance equation is solved numerically for sea-level temperature $T$ as a function of latitude and month (similar to North, 1975). Seasonally varying snow cover (which affects planetary albedo) is included diagnostically by parameterizing monthly snowfall and snowmelt in simple ways. The net annual accumulation and ablation on the ice sheet surface at each latitude are computed using the same parameterizations as for snow cover above (with $T$ corrected for ice sheet height using a lapse rate of $-6.5^{\circ} \mathrm{C} \mathrm{km}^{-1}$ ). Treatment of the ice sheets follows Weertman (1976) with ice flow approximated as perfect plasticity, which constrains the ice sheet profiles to be parabolic. The northern hemisphere's ice sheet is constrained to extend equatorward from $75^{\circ} \mathrm{N}$ (corresponding to the Arctic Ocean shoreline).

Model ice age curves are generated for the last several 100 Kyears by computing the seasonal climate as above once every 2 Kyears, with insolation calculated from actual Earth orbit perturbations. The change in ice sheet size for each 2 Kyear time step depends only on the net annual snow budget integrated over the whole ice sheet surface. In these model runs, the equatorward tip of the northern hemisphere's ice sheet oscillates through $\sim 7^{\circ}$ in latitude, correctly simulating the phases and approximate amplitude of the higher frequency components ( $43 \mathrm{Kyear}$ and $22 \mathrm{Kyear}$ ) of the deep-sea core data (Hays et al., 1976). However, the model fails to simulate the dominant glacial-interglacial cycles ( $\sim 100$ to 120 Kyear) of this data. The sensitivity of the model ice age curves to various parameter changes is described, but none of these changes significantly improve the fit of the model ice age curves to the data. In the concluding section we generalize about the types of mechanisms that might yield realistic glacial-interglacial cycles.
\end{abstract}

\section{Introduction and summary}

There is little agreement as yet on the dominant causes of the Quaternary ice ages, although many mechanisms have been suggested (described in Beckinsale, 1973; Andrews, 1975, p. 71). Data from deep-sea sediment cores provide continuous records of some climatic variables over the last several 100 Kyears (e.g., Broecker and Van Donk, 1970; Hays et al., 1976; Emiliani, 1978). These

\footnotetext{
${ }^{1}$ Contribution number 3344 of the Division of Geological and Planetary Sciences, California Institute of Technology, Pasadena, California 91125 , U.S.A.
}

records of global ice sheet volume have been interpreted as showing quasi-periodic glacial-interglacial cycles with fast retreats from maximum to minimum volumes occurring at intervals of approximately 100 to 120 Kyears; superimposed on these cycles are secondary oscillations with smaller amplitudes and higher frequencies. Others have cautioned that some or all of the fluctuations in these records may not be periodic but essentially random (e.g., Shackleton, 1969, p. 145; Lemke, 1977). In any case, these continuous records are suitable for comparisons against any simulated records generated by quantitative models formulated to test the various suggested ice age mechanisms. 
One such mechanism, the "astronomical" or "Milankovitch" theory, involves variations of incoming solar insolation due to the secular perturbations of the Earth's orbit. These variations are the only well-known external forcing of climate on ice age time scales. The historical development of the astronomical theory is lucidly described in Imbrie and Imbrie (1979). Milankovitch estimated the sensitivity of climate to this forcing using insolation-curve computations (e.g., Milankovitch, 1941), and these insolation-curves have been refined and extended by Van Woerkom (1953), Vernekar (1972), Berger (1978) and others. Other recent investigations have used seasonal climate models (Shaw and Donn, 1968; Budyko and Vasishcheva, 1971; Saltzman and Vernekar, 1971; Suarez and Held, 1976, 1979; Schneider and Thompson, 1979), explicit ice sheet models (Weertman, 1976; Birchfield and Weertman, 1978), a combined seasonal climate-ice sheet model (Pollard, 1978), and a combined annual mean climate-ice sheet-ocean model (Sergin, 1979). Also Calder (1974) and Imbrie and Imbrie (1980) have used single non-explicit "response equations". Most of these studies have generated simulated ice age curves of one sort or another, and comparisons with deep-sea core records consistently indicate that the astronomical forcing can account for the observed secondary oscillations; this positive result is consistent with the power spectrum analyses of Hays et al. (1976) and Kominz and Pisias (1979) (but see Evans and Freeland, 1977). However, none of the models above have correctly simulated the dominant glacial-interglacial cycles of the records as a response to the astronomical forcing.

This paper reports on a combined seasonal climate-ice sheet model that was described briefly in a preliminary paper (Pollard, 1978). We had hoped that the additional non-linearity due to the interactions between the ice sheets and the seasonal cycle might be the missing factor required to produce realistic glacial-interglacial cycles. With this motivation we explored the model's sensitivity to a systematic range of parameter variations. In Section 2 below, the model is formulated and its solution for the present seasonal climate is described. In Section 3, the model's long-term response to the orbital perturbations is presented, and in Section 4 we describe the sensitivity of this response to small changes in various parameter values and types of parameterizations. In these sections we emphasize some differences between these sensitivities and those of some other climate models, and suggest which differences in the models can account for the different sensitivities. Although our parameter changes have relatively slight effects on the fit to the present climate, some of them have significant effects on the model's simulated ice age curves, i.e., on its long-term response to the astronomical forcing. Over most of the parameter ranges these curves retain the secondary oscillations observed in the deep-sea core records; however, with the model in its present form we are still unable to generate any curves resembling the observed dominant glacial-interglacial cycles.

Therefore, this paper supports the results of the earlier studies mentioned above. Further, since the present model still cannot account for the glacialinterglacial cycles, we suggest in Section 5 that one or more other long-term mechanisms may be important.

\section{Model formulation and present-day results}

The model has previously been outlined in Pollard (1978). There are two distinct parts corresponding to the two distinct time-scales of the global seasonal climate and the long-term ice sheet response. In Sections 2.1, 2.2 and 2.3 the seasonal part of the model and its solution for the present climate are described, and in Section 2.4 the ice sheets are incorporated into the model.

\subsection{Seasonal energy-balance equation}

Following North (1975), the climate through one year over a spherical globe is described by a zonally averaged, one-level energy-balance equation for sea-level air temperature $T$ :

$$
\begin{aligned}
& \frac{\partial}{\partial t}[C T(x, t)]-\frac{\partial}{\partial x}\left[\left(1-x^{2}\right) \frac{D}{R^{2}} \frac{\partial}{\partial x}(C T)\right] \\
& +[A+B T]=Q(x, t)(1-a)+S
\end{aligned}
$$

Here $x$ is $\sin$ (latitude) and $t$ is time. All dependent variables are defined as $\sim 1$ month running-means, so daily correlations are effectively assumed constant. Boundary conditions are $\left(1-x^{2}\right)^{1 / 2} \partial T / \partial x=$ 
0 at the poles $x= \pm 1$ (Hantel, 1972). Other symbols and their values for our "standard" model are:

$C=4.6 \times 10^{7} \mathrm{~J} \mathrm{~m}^{-2}{ }^{\circ} \mathrm{C}^{-1}$, a constant seasonal heat capacity of the atmosphere-land-ocean system (equivalent to a layer of liquid water 11 m thick).

$D=0.501 \times 10^{6} \mathrm{~m}^{2} \mathrm{~s}^{-1}$, a linear diffusion coefficient acting over the whole thickness of the layer represented by $C$.

$R=6.36 \times 10^{6} \mathrm{~m}$, radius of the Earth.

$A=207 \mathrm{~W} \mathrm{~m}^{-2}, B=1.9 \mathrm{~W} \mathrm{~m}^{-2}{ }^{\circ} \mathrm{C}^{-1}$, net infrared radiation coefficients.

$Q=$ zonal mean insolation at the top of the atmosphere, computed for any given era from the orbital elements in Berger (1976) using a solar constant of $1360 \mathrm{~W} \mathrm{~m}^{-2}$.

$a=r a_{c}+(1-r) a_{f}$, earth-atmosphere albedo. $a_{c}$ $=0.62$ represents areas covered by seasonal snow or ice sheet (see below), and $a_{\mathrm{f}}=0.31+$ $0.08\left[\left(3 x^{2}-1\right) / 2\right]$ represents areas free of seasonal snow and ice sheet. We set $r=1$ north of $75^{\circ} \mathrm{N}$ to represent perennial Arctic Ocean sea-ice (Ku and Broecker, 1967; Hunkins et al., 1971), and $r=1$ south of $70^{\circ} \mathrm{S}$ to represent a fixed Antarctic ice sheet (see below). At all other latitudes $r=0.6$ when covered by seasonal snow or ice sheet, and $r=$ 0 when free of seasonal snow and ice sheet.

$S=1.27\left[\mathrm{~J} \mathrm{~m}^{-2} \mathrm{~s}^{-1}\right]$ per $\left[\mathrm{g} \mathrm{cm}^{-2}\right.$ month $\left.^{-1}\right]$, representing latent heat of fusion released or required at each latitude by the varying amount of seasonal snow cover (see below). The annual mean of $S$ at each latitude is zero.

Most of these parameterizations [discussed for instance in Coakley (1979)] have found general use in many annual mean energy-balance models and are based on annual mean data. There is currently some doubt about the physical basis of the diffusive heat parameterization (Van Loon, 1979), but it may be valid for global and seasonal scales (Hartjenstein and Egger, 1979; Lorenz, 1979). The infrared radiation and albedo parameterizations are found to represent seasonal data less accurately than annual mean data, possibly due to independently varying cloud cover (White, 1976; Warren and Schneider, 1979), but we use them here for simplicity. We also neglect possible variations of cloud cover in past eras, which might be serious for the ice age problem. Unfortunately, considerable uncertainty exists for the prediction of cloud amounts even in much more complex models.

\subsection{Seasonal snowmelt and snowfall}

Seasonally varying snow cover on land at sea-level is modelled diagnostically by parameterizing monthly snowmelt and snowfall as functions of the current air temperature $T$ and insolation $Q$. We use

$$
\text { Snowmelt }\left(\mathrm{g} \mathrm{cm}^{-2} \text { month }^{-1}\right)=\max \left[0 ; a T\left({ }^{\circ} \mathrm{C}\right)\right.
$$$$
\left.+b Q\left(\mathrm{~W} \mathrm{~m}^{-2}\right)+c\right]
$$

Equation (2) is basically an energy-balance equation for a melting snow/ice surface with seasonal heat storage neglected, and as such is equivalent to the snowmelt parameterization of Suarez (1976). Equation (2) is also used below for the monthly ablation on ice sheet surfaces (Section 2.4). For the standard model we use $a=10, b=$ $0.32, c=-47$; these values and the adequacy of this parameterization for the ice age problem are discussed in more detail in Pollard (1980).

Whereas snowmelt is a micrometeorological process, snowfall depends on synoptic-scale processes and the basic dependence of past and seasonal variations of snowfall on the zonally averaged variables $T$ and $Q$ is not nearly so apparent as for snowmelt. For this reason [and following Suarez (1976)] we set

$$
\begin{gathered}
\text { Snowfall ( } \left.\mathrm{g} \mathrm{cm}^{-2} \text { month }^{-1}\right) \\
=\left\{\begin{array}{cl}
P(\text { lat. }) & \text { if } T \leq 0^{\circ} \mathrm{C} \\
0 & \text { if } T>0^{\circ} \mathrm{C}
\end{array}\right.
\end{gathered}
$$

where $P$ is the present observed zonal and annual mean precipitation rate at each latitude. The northern hemispheric data given in Schutz and Gates (1971-4) is used for $P($ lat.) in both model hemispheres, since the present precipitation in south polar regions is clearly affected by Antarctic topography. Equation (3) is also used for the monthly accumulation on ice sheet surfaces in the standard model (Section 2.4), but some effects of ice sheet topography on the local accumulation rate will be included later.

For simplicity the model neglects variations of sea-ice. Although this might be serious for the ice age problem, seasonal and past variations of sea-ice in the northern hemisphere are somewhat smaller (by factors of $\sim 2$ to 3 ) than those of seasonal snow 
cover and ice sheets on land (Flint, 1971, figs. 4.8, 4.9; Emiliani and Geiss, 1957, table 2; Saltzman and Vernekar, 1975, table 1).

\subsection{Fit to present climate}

As in North (1975) and North and Coakley (1979), the solution of eq. (1) is simplified by expressing the latitudinal dependences of $T$ and the right-hand forcing in terms of the eigenfunctions of the spherical diffusion operator. Only the first three eigenfunctions are kept li.e., Legendre polynomials $1, x$, and $\left(3 x^{2}-1\right) / 2$, since any finer latitudinal resolution would probably not be realistic due to the coarse parameterizations used. However, the diagnostic snow budget parameterizations (2) and (3) prevent a corresponding convenient Fourier expansion in time $t$ (cf. North and Coakley, 1979). Equation (1) is numerically integrated forward in time-steps of 1 month through consecutive years until initial transients decay to negligible levels and a repeated seasonal cycle is attained (usually after $\sim 10$ years).

Fig. 1 shows the sea-level temperature solution of the standard model, for the present orbital elements and with no northern hemispheric ice sheet. For comparison table la in Warren and Schneider (1979) shows the equivalent data for surface air temperature. The parameter values of the standard model given above were chosen to fit the present temperature data of the northern hemisphere. With the infrared radiation, albedo and snow budget parameterizations all fixed (somewhat arbitrarily), $C$ was adjusted to yield realistic seasonal amplitudes at mid and high latitudes and $D$ was adjusted to yield realistic latitudinal gradients.

The most obvious discrepancy in Fig. 1 from reality is the excessive seasonal amplitudes in the southern hemisphere due to the uniform value of $C$; in this respect our climate model is effectively two northern hemispheres patched together. The seasonal snow cover in the model southern hemisphere is only a crude analogy for the seasonal variation of sea-ice around Antarctica. Perhaps more seriously for the application to the Milankovitch theory, the model seasonal cycle in both hemispheres is lagged $\sim 2$ months behind the insolation cycle, which is about $\sim 1$ month more than observed in the northern hemisphere. This excessive lag has also been found by North and Coakley (1979) and Thompson and Schneider

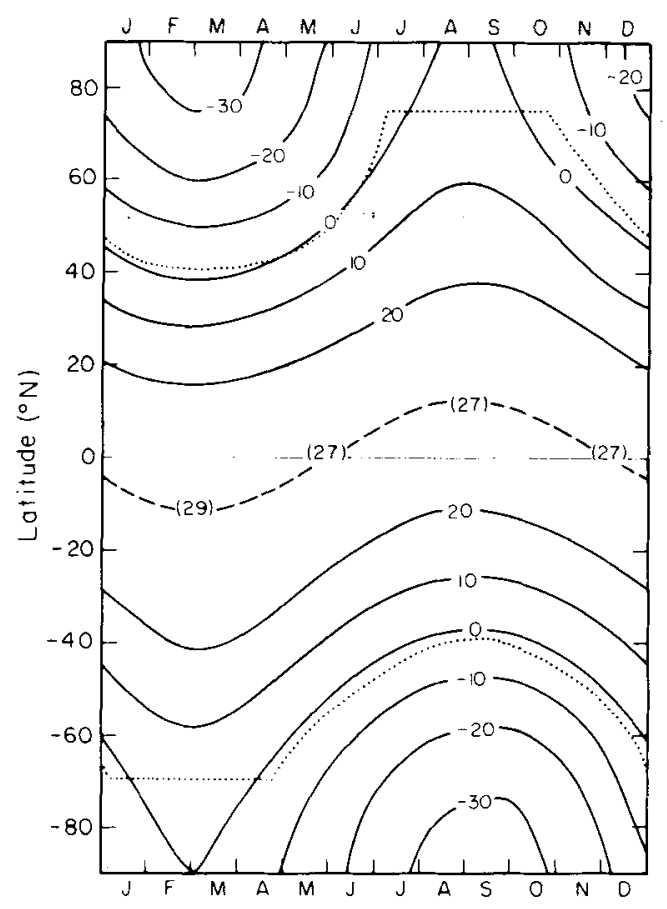

Fig. I. Zonal mean sea-level temperature vs latitude and month for standard model present-day solution. Values shown are degrees centigrade. The dashed curve shows the latitudes of maximum temperature at each month, with maximum temperature values for some months in parentheses. The dotted curves show the latitudinal extents of seasonal snow cover in each hemisphere, for the months when snow exists equatorward of the limits of the Arctic Ocean $\left(75^{\circ} \mathrm{N}\right)$ or Antarctic ice sheet $\left(70^{\circ} \mathrm{S}\right)$.

(1979) in their simplest model versions, and is related to the lack of any longitudinal contrast in seasonal heat capacity between land and ocean. This excessive lag is reflected in the seasonal snow line shown in Fig. 1; the onset of snow in autumn is $\sim 1$ month later than observed (Kukla, 1975).

Fig. 2 plots the net annual "potential" snow budget for the northern hemisphere corresponding to the present-day solution. This shows the net annual snowfall minus snowmelt that would occur on any mountain glacier or ice cap surface at a given latitude and elevation $h$, calculated for each month from (2) and (3) but with $T$ corrected to $T$ $6.5\left({ }^{\circ} \mathrm{C} \mathrm{km}^{-1}\right) \cdot h$ to allow for the atmospheric lapse rate. (Of course, snowmelt can continue below the nominal level for these surfaces so that negative net annual budgets are possible.) The zero-budget line generally agrees with present data such as the 


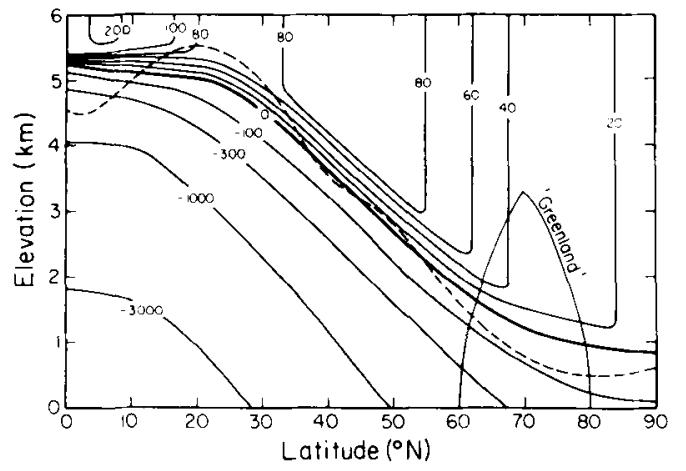

Fig. 2. Net annual snow accumulation minus ablation that would occur in the model present-day solution on hypothetical ice surfaces at given latitudes and elevations. Values shown are $\mathrm{g} \mathrm{cm}^{-2}$ year $^{-1}$. A model ice sheet profile given by (4) roughly representing Greenland is also shown, although its contribution to the albedo $a$ in (1) was ignored for the present-day solution. The dashed line is the observed "regional snowline" of Paschinger (1912), redrawn from Sugden and John (1975, Fig. 5.5).

generalized "regional snowline" (Paschinger, 1912), glacier altitudes in western U.S.A. (Meier, 1960), and the altitude of the equilibrium line in southern Greenland (Schuster, 1954). However, the model zero-budget line is $\sim 500 \mathrm{~m}$ too high in polar latitudes north of $\sim 70^{\circ} \mathrm{N}$. There are few estimates of the present net annual budget for the entire Greenland ice sheet; approximately half of the total mass loss is by the calving of icebergs (Paterson, 1969, p. 228). The net annual accumulation minus ablation for the model Greenland profile in Fig. 2 averages to $-4 \mathrm{~g} \mathrm{~cm}^{-2}$ over the southern half and $+21 \mathrm{~g} \mathrm{~cm}^{-2}$ over the northern half.

\subsection{Ice sheets}

Ice sheets are incorporated into the climate model following Weertman's $(1964,1976)$ simple treatment. Ice sheet flow under its own weight is approximated to be perfectly plastic, which constrains the model ice sheet profiles to always remain parabolic:

$h(s)=[\lambda(L-|s|)]^{1 / 2}$

where $h$ is the elevation of the ice sheet surface above sea-level, $L$ is the half-width and $s$ is the latitudinal distance from the ice sheet center (with $s$ taken positive towards the equator). The ice sheet base is assumed to be isostatically depressed to depths $0.5 h(s)$ below sea-level. $\lambda$ is a constant proportional to the yield stress of ice; for our standard model we use $\lambda=10 \mathrm{~m}$, corresponding to a yield stress of $\sim 0.7$ bars. This value is slightly less than in Weertman (1976) but still gives somewhat greater central thicknesses (by $\sim 30 \%$ ) than those modelled by Paterson (1972) and those suggested by Greenland and Antarctica today.

One model ice sheet, representing the Laurentide and Scandinavian ice sheets of past eras, is constrained to extend equatorward with its northern tip fixed at $75^{\circ} \mathrm{N}$ (corresponding to the Arctic Ocean shoreline). Where the margins of the real northern hemispheric ice sheets reached continental coastlines, further advance was prevented by rapid iceshelf and iceberg calving into the ocean, but their equatorial extent and overall volume were probably limited more by ablation on their southern flanks (cf. Flint, 1971, p. 484, 600). Therefore, as in Weertman (1976), the long-term variation in the model ice sheet size is controlled by the net accumulation (snowfall) minus ablation (mostly snowmelt) on its southern half only (i.e., $s$ $>0$ ). Also, since its profile is constrained by (4), any change in size is determined simply by the total ice volume added to or removed from the entire southern half. Writing the net annual accumulation minus ablation (per unit surface area) as $m(s)$, then the change in ice sheet size per unit long-term time increment $d \tau$ is given by:

$\frac{d V}{d \tau}=\frac{d}{d \tau}\left[\lambda^{1 / 2} L^{3 / 2}\right]=\frac{1}{\rho} \int_{0}^{L} \frac{m(s)}{(1 \text { year })} d s$

$V$ is the volume of the southern half of the ice sheet (per unit longitudinal distance), related to $L$ from (4). $\rho$ is the mean ice sheet density, taken as $0.9 \mathrm{~g}$ $\mathrm{cm}^{-3}$.

The other model ice sheet representing Antarctica is circular and centered on the South Pole. The existing Antarctic ice sheet is prevented from advancing beyond the continental bedrock by rapid calving into the southern oceans, so we do not allow this model ice sheet to ever extend equatorward beyond $70^{\circ} \mathrm{S}$. In fact, the ice sheet remains at this maximum size in all ice age runs shown below, since its net annual budget is always positive. Significant ice age fluctuations in the real Antarctic ice sheet might have occurred (e.g., Wilson, 1964), but we defer this possibility to future model developments.

Model ice age curves are generated by solving (1) for one year's "climate" $T(x, t)$ once at the start 
of each long-term time-step $d \tau$, using the current orbital elements. The presence of the ice sheets influences $T$ only through the albedo $a$. The monthly snowmelt and snowfall at any point on the ice sheet surface is given by (2) and (3) with $T$ corrected to $T-6.5\left({ }^{\circ} \mathrm{C} \mathrm{km}^{-1}\right) \cdot h$ and with $h$ given by (4). These values are integrated to give the net annual snow budget for the northern hemispheric ice sheet which is then used in (5) to determine the change in its size over the next $d \tau$ years. For all ice age curves below, we used $d \tau=2$ Kyears. This type of procedure involving two distinct climatic time scales is described more formally in Hasselmann (1976), and has been applied to the ice age problem by Eriksson (1968) using a generalized analytical approach.

\section{Ice age results: Standard model}

\subsection{Ice sheet response}

The ice age simulation produced for the last 400 $\mathrm{Kyears}$ by our standard model is compared in Fig. 3 with a $\delta^{18} \mathrm{O}$ deep-sea core record from Hays et al. (1976). The model curve of northern hemispheric ice sheet volume reflects the forcing of both obliquity ( $\sim 41$ Kyear period) and precession ( 22 Kyear period), with obliquity dominating in times of small eccentricity (e.g., 60 to 0 Kyears BP). [The response of an ice sheet model to individual sinusoidal forcings with these periods has been described by Birchfield (1977).] The model ice sheet curve closely resembles an equivalent ice sheet curve in Weertman (1976, his fig. 6) and also the response-curves in Imbrie and Imbrie (1980), and coincides both in phase and approximate amplitude with the secondary oscillations of the $\delta^{18} \mathrm{O}$ record. The long-term volume inertia of the ice sheets has produced a phase lag of $\sim 5$ to 10 Kyears behind the orbital forcing (by visual comparison with various insolation-curves), consistent with the measured phase relationships in Hays et al. (1976). But despite its explicit seasonal climate treatment, our model still lacks the dominant glacial-interglacial cycles and the drastic ice sheet retreats (e.g., 18 to 0 Kyears BP), in common with Weertman's and Birchfield's models.

In all ice age runs the pattern of net annual accumulation minus ablation cver the ice sheets remains the same as that shown for Greenland in Fig. 2, i.e., widespread net accumulation over the central regions and much stronger net ablation over a relatively narrow strip near the equatorward tip. Therefore, the non-linear possibility suggested by Weertman (1964), of retreating ice sheets becoming

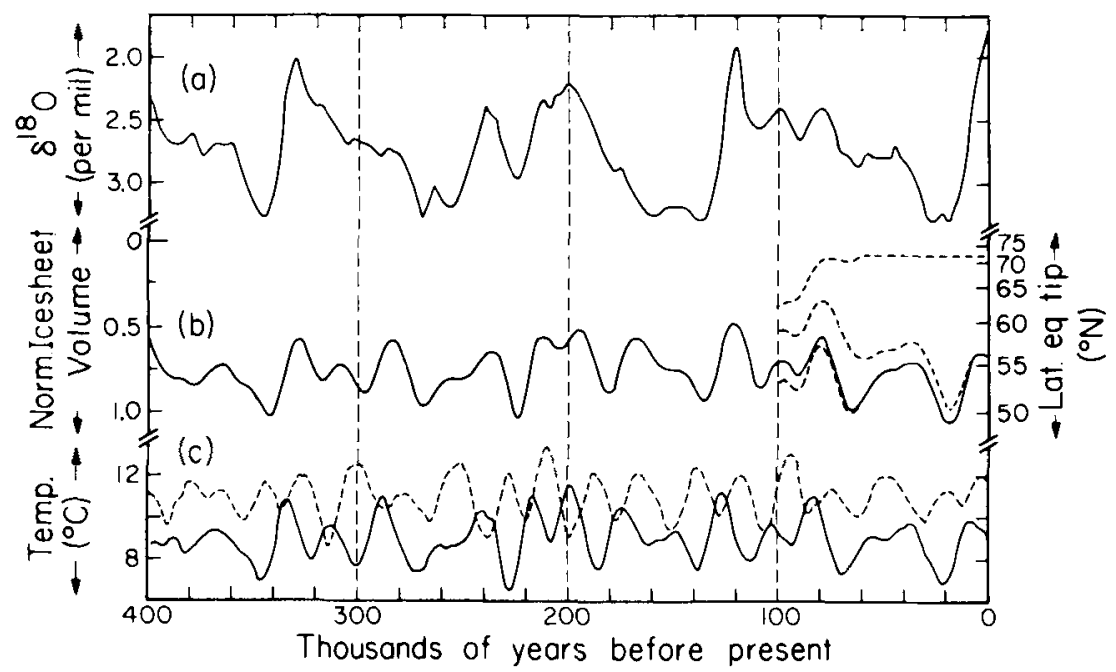

Fig. 3. (a) $\delta^{18} \mathrm{O}$ recorded from two combined deep-sea cores (from $\sim 45^{\circ} \mathrm{S}$ lat.), redrawn from Hays et al. (1976, Fig. 9). (b) Ice age curve for standard model, showing northern hemispheric ice sheet volume normalized by its volume with equatorward tip at $50^{\circ} \mathrm{N}$. Right-hand scale shows corresponding latitudes of its equatorward tip. The dashed curves from 100 to 0 Kyears BP show the effect of choosing different initial ice sheet sizes at 100 Kyears BP. (c) Maximum (monthly mean) sea-level temperature at $55^{\circ} \mathrm{N}$ (solid curve) and $55^{\circ} \mathrm{S}$ (dashed curve), corresponding to the ice age run in (b). 
stagnant and thus having a shorter shrinkage time-scale than growth time-scale, does not occur in any of our model runs. Imbrie and Imbrie's (1980) "response-equation" does contain such a non-linearity and produces some suggestions of glacial-interglacial cycles and drastic ice sheet retreats in response to the eccentricity variations. Consequently their fit to the $\delta^{18} \mathrm{O}$ record is slightly better than ours, but stills leaves room for improvement.

The effect of orbital changes on the standard model can be viewed in another way in Fig. 4. Each curve shows how the northern hemispheric ice sheet would grow or recede as a function of its size, for various combinations of the orbital elements. This figure is a development of fig. 7 in Weertman (1961), who analyzed the general shape of the curves as a simple geometrical consequence of ice sheet topography and the typical net snow budget pattern. As expected (Berger, 1978), the grouping of the curves in Fig. 4 shows that eccentricity plus precession are most important for large (low latitude) ice sheets, whereas obliquity has an important effect for small (high latitude) ice sheets. For fixed orbital elements, the ice sheet size would move along the relevant curve until it either arrives at a stable point $S$ or is ablated away to the Arctic shoreline. The ice sheet tip in the ice age run of Fig.
3 (b) varies between $\sim 50^{\circ} \mathrm{N}$ and $\sim 60^{\circ} \mathrm{N}$, and this is the region in Fig. 4 where approximately half of the orbital combinations are enlarging the ice sheet towards stable points $S$ and the other half are ablating it toward the Arctic shoreline. However, this potential amplitude of some $30^{\circ}$ in latitude implied by Fig. 4 is reduced to $\sim 10^{\circ}$ latitude in Fig. 3 (b) by the volume inertia of the ice sheet.

The full amplitude of $\sim 30^{\circ}$ in latitude is reflected in the dashed curves in Fig. 3 (b), which show the effect of choosing different initial ice sheet sizes at $100 \mathrm{Kyears}$ BP. If the initial tip position is north of $\sim 61 \%$. $\mathrm{N}$, the ice sheet does not return to the solid curve. Instead it is ablated back to the Arctic shoreline and remains there forever, since the majority of orbital combinations produce negative regimes for these small ice sheet sizes. This is an example of an "intransitive" climate system (Lorenz, 1970), with two possible stable branches depending on the initial conditions. The orbital forcing by itself is insufficient to produce transitions from one branch to another, and so we effectively had to "choose" the ice-sheet-free branch for the presentday fit in Section 2.3, and the other branch exhibiting ice sheet oscillations for this section. Some modifications described below will make these transitions possible (Fig. 10) or will eliminate the distinction between the two branches (Fig. 8).

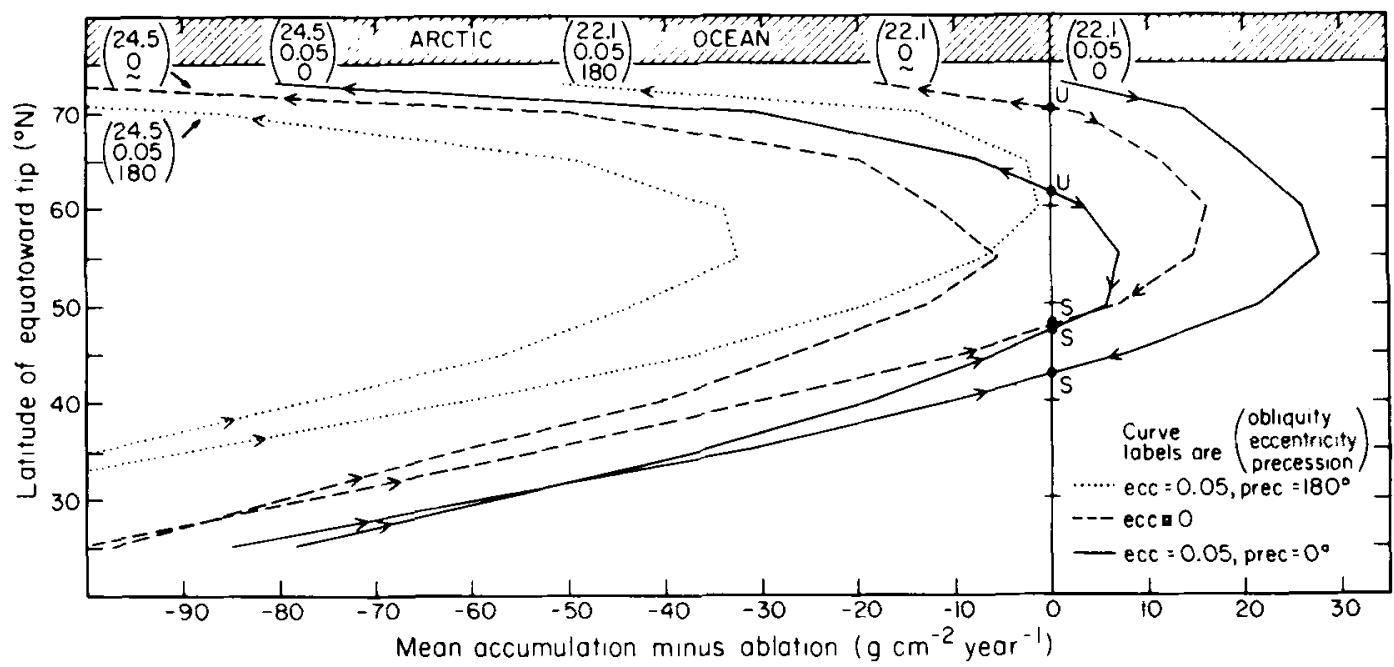

Fig. 4. Curves of net annual northern hemispheric ice sheet budget (averaged over southern half) as functions of its size, for various combinations of the orbital elements. (Precession is defined here so that it is zero when the northern hemispheric winter solstice coincides with perihelion, and $180^{\circ}$ when this solstice coincides with aphelion.) These curves are for the standard model. For fixed orbital elements, " $S$ " are stable equilibrium points, " $U$ " are unstable equilibrium points, and the arrows show directions of ice sheet growth and decay.

Tellus 32 (1980), 4 
The time-scale on which the dashed curves in Fig. 3 (b) converge onto one branch or another is on the order of $\sim 40$ Kyears. This represents the intrinsic time-scale of the quasi-linear ice sheet response on either branch, and is roughly consistent with the amount of lag (mentioned above) of the solid curve in Fig. 3 (b) behind the orbital forcing. Because the model has only one long-term time-derivative [in (5)], there can be no free internal oscillations of the system in the absence of external forcing, as there are in Sergin's (1979) climateocean-ice sheet model.

\subsection{Temperature response}

Fig. 3 (c) shows the variation of maximum summer temperature at particular latitudes for the standard ice age run. The temperature curve for $55^{\circ} \mathrm{N}$ seems (visually) to lag only $\sim 0$ to 4 Kyears behind the orbital forcing, considerably less than the ice sheet volume curve. This summer temperature curve has roughly the same phase as various northern hemispheric curves in Shaw and Donn (1968), Suarez and Held (1979) and Schneider and Thompson (1979). The higher-frequency component of the temperature curve for $55^{\circ} \mathrm{S}$ reflects the forcing of precession, which is $180^{\circ}$ out of phase between the two hemispheres. The phase of the $55^{\circ} \mathrm{S}$ curve does not agree with that of the secondary oscillations of the " $T \mathrm{~s}$ " deep-sea core record for $\sim 45^{\circ} \mathrm{S}$ in Hays et al. (1976); the latter is found to lead those of the $\delta^{18} \mathrm{O}$ core record by $\sim 2$
Kyears. This disagreement may be due to the shortcomings in the model formulation for the southern hemisphere. [Both Suarez and Held's (1979) and Schneider and Thompson's (1979) models have realistic southern hemispheric seasonal heat capacities, but they appear to yield southern hemispheric temperature phases that are opposite to each other.]

Table 1 summarizes the sensitivity of northern hemispheric temperatures to some particular changes in the orbit and ice sheet size (analogous to Fig. 4). The most extreme orbital variation with no northern hemispheric ice sheet (col. 4, Table 1) causes seasonal temperature changes comparable to those caused through the albedo $a$ by a full glacial-interglacial ice sheet variation at fixed orbit (col. 5, Table 1). However this ice sheet variation causes annual mean temperature changes at mid and high latitudes that are considerably larger than those caused by the orbital variations, in agreement with the trend in Sergin (1979, fig. 16).

We now compare the sensitivities in Table 1 to those of other models. The sensitivities of annual mean temperatures to the orbital variations (cols. 2 to 4, Table 1) are similar to those of Schneider and Thompson's (1979) model, but are generally less than $1 / 4$ of those in Suarez and Held (1979). The extra sensitivity in the latter model is probably due to greater albedo feedback of seasonal snow. As discussed by Suarez and Held, albedo feedback is greater for models like theirs having realistic land-ocean longitudinal contrast. However in

Table 1. Differences of sea-level temperatures at particular latitudes between different orbits (as defined in Fig. 4) with no northern hemispheric ice sheet (columns 2 to 4), and between different ice sheet sizes with the same orbit (column 5)

\begin{tabular}{lccccc}
\hline Latitude & $\left.\begin{array}{c}\delta \text { orbit } \\
24.5 \\
0 \\
-\end{array}\right)-\left(\begin{array}{c}22.1 \\
0 \\
\sim\end{array}\right)$ & $\left.\begin{array}{l}\delta \text { orbit } \\
22.1 \\
0.05 \\
180\end{array}\right)-\left(\begin{array}{l}22.1 \\
0.05 \\
0\end{array}\right)$ & $\left.\begin{array}{l}\delta \text { orbit } \\
24.5 \\
0.05 \\
180\end{array}\right)-\left(\begin{array}{l}22.1 \\
0.05 \\
0\end{array}\right)$ & $\begin{array}{l}\delta \text { ice sheet tip } \\
\left(73^{\circ} \mathrm{N}-50^{\circ} \mathrm{N}\right)\end{array}$ \\
\hline $89^{\circ} \mathrm{N}$ & $\left(\begin{array}{r}3.4 \\
-0.7\end{array}\right) \quad 1.1$ & $\left(\begin{array}{r}2.5 \\
-2.4\end{array}\right)-0.4$ & $\left(\begin{array}{r}5.8 \\
-3.1\end{array}\right) 0.7$ & $\left(\begin{array}{l}6.1 \\
2.5\end{array}\right) 4.0$ \\
$45^{\circ} \mathrm{N}$ & $\left(\begin{array}{r}1.6 \\
-1.1\end{array}\right) \quad 0.1$ & $\left(\begin{array}{r}4.5 \\
-4.1\end{array}\right)-0.3$ & $\left(\begin{array}{r}6.1 \\
-5.1\end{array}\right)-0.1$ & $\left(\begin{array}{l}3.8 \\
2.1\end{array}\right) 2.6$ \\
$1^{\circ} \mathrm{N}$ & $\left(\begin{array}{l}-0.9 \\
-0.7\end{array}\right)-0.7$ & $\left(\begin{array}{r}6.0 \\
-5.9\end{array}\right)$ & 0.0 & $\left(\begin{array}{r}5.2 \\
-6.6\end{array}\right)-0.7$ & $\left(\begin{array}{l}0.4 \\
0.7\end{array}\right) 0.6$
\end{tabular}

The values in parentheses are differences in ${ }^{\circ} \mathrm{C}$ for the months of maximum northern hemispheric summer temperatures (upper value) and minimum northern hemispheric winter temperatures (lower value). The other value outside the parentheses is the annual mean temperature difference in ${ }^{\circ} \mathrm{C}$. 
addition to this effect, Suarez and Held have adjusted their parameter values so that over nearly the whole range of orbital variations, their northern hemispheric minimum summer snowline remains equatorward of the Arctic Ocean; in contrast, our model solutions (for cols. 2 to 4, Table 1) have no seasonal snow (i.e., no albedo feedback) in summer equatorward of our Arctic Ocean shoreline at $75^{\circ} \mathrm{N}$, as in Fig. 1. The real summer snowline seems to be roughly intermediate between these two model situations (Dickson and Posey, 1967; Kukla, 1975; Williams, 1978).

The reductions of $T$ in summer due to the ice sheets (col. 5, Table 1) are comparable to those found by CLIMAP (1976) data for sea-surface temperatures of the last glacial maximum. The corresponding air temperature reductions found by the more complex zonal model of Saltzman and Vernekar (1975) and the GCM of Gates (1976a,b) are generally larger than in col. 5 (by $\sim 100 \%$ ), whereas the GCM of Williams (1974) has found much larger air temperature reductions (of $Z 20^{\circ} \mathrm{C}$ ).

These differences in the temperature sensitivities of the various models lead to some uncertainty in applications to the Milankovitch theory. For instance, it may be that if we replaced our simple climate model with Suarez and Held's model, the amplitude of the ice sheet response in Fig. 3 (b) (as well as the annual mean temperature response) would be increased by a factor of $\sim 4$. However, our simple model already realistically simulates the secondary oscillations of the $\delta^{18} \mathrm{O}$ data, and any large alteration of its ice sheet sensitivity would destroy this agreement. What is needed is a model modification to produce the dominant glacialinterglacial cycles of the data.

\section{Ice age results: parameter sensitivity}

The aim of this section is to explore the range of parameter values and parameterizations that still yield realistic ice age secondary oscillations, and also to search for a model modification that may produce the full glacial-interglacial cycles. We do not concentrate on the sensitivity of particular climate solutions $T(x, t)$ per se. Most of the parameter changes examined below do slightly perturb the present-day solution of Section 2.3 (e.g., by $\lesssim \pm 2^{\circ} \mathrm{C}$ in Fig. 1 , by $\leqslant \pm 500 \mathrm{~m}$ in the zero-budget line altitude in Fig. 2), but these perturbations are minor compared to the existing coarseness of the fit to present data.

\subsection{Climate parameter variations}

Fig. 5 shows the sensitivity of the ice age curve to small variations in the diffusion parameter $D$, with all other parameters held constant. Only the response for the last $100 \mathrm{Kyears}$ is shown, but this is sufficient to demonstrate the behavior for any time period. We have performed the same exercise for small variations $(\sim 2$ to $10 \%)$ in each one of the "climate parameters" $C, B, a_{\mathrm{f}}, a_{\mathrm{c}}, a, b$, and $c$ [appearing in (1) and (2)] in turn, all with virtually the same result as in Fig. 5.

For parameter changes that have the effect of reducing the summer temperatures in mid and high latitudes or reducing ablation for a given temperature and insolation, the mean position of the ice age curves move smoothly equatorward. The effect of precession ( 22 Kyear period) becomes more pronounced equatorward of $\sim 45^{\circ} \mathrm{N}$, as might be expected from Fig. 4. Apart from this effect, the basic model response is unchanged and still resembles the secondary oscillations of the ice age data. (For larger parameter variations than shown here, a sudden transition to ice-sheet-covered northern hemispheric continents might be expected. In other runs (not shown) investigating solar constant variations, ice sheets could exist in stable equilibrium down to $\sim 20^{\circ} \mathrm{N}$ for solar constant reductions of up to $\sim 5 \%$, beyond which they grew down to the equator.] For parameter changes in the other direction, there is a sudden transition to an ice-sheet-free northern hemisphere; there is no stable mean ice sheet tip position between $\sim 55^{\circ} \mathrm{N}$ and the Arctic shoreline. Once the minimum size is reached, the ice sheet never grows out again [as in Fig. 3 (b)].

The behavior in Fig. 5 can be explained by referring to Fig. 4. Climate parameter variations basically have the effect of shifting the pattern of curves in Fig. 4 horizontally relative to the "regime" $x$-axis. For small shifts toward more negative regimes, ice sheet sizes in the range $\sim 50^{\circ}$ to $60^{\circ} \mathrm{N}$ begin to lie more on the unstable ablating branches of most orbital curves, and so are reduced back to the Arctic shoreline. For relatively large shifts toward more positive regimes, more orbital curves have stable points $S$ and the range of latitudes of these stable points smoothly moves equatorward. 


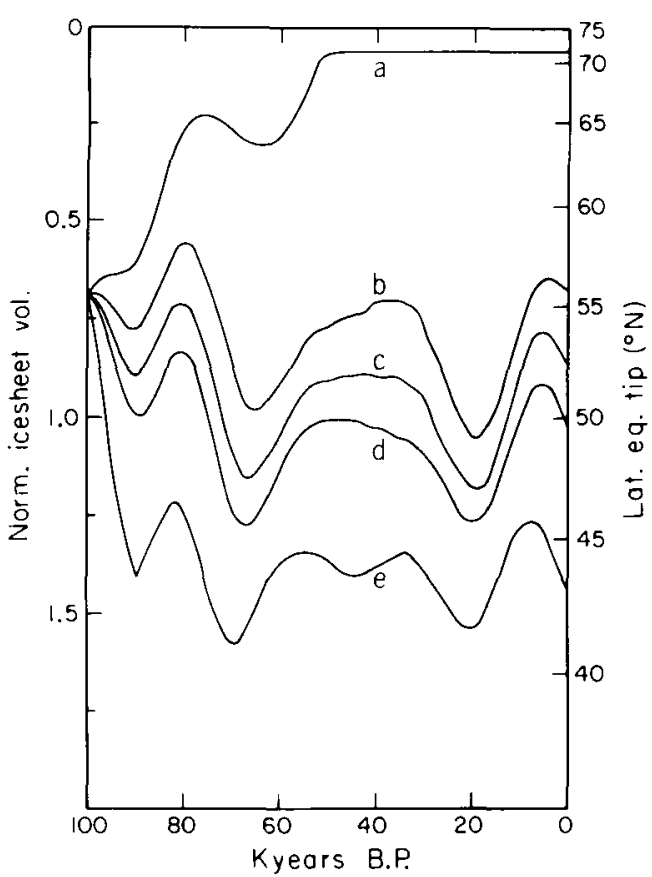

Fig. 5. Ice age curves for the standard model except: (a) Diffusion coefficient $D=(0.31 / 0.30) \times$ standard model value. (b) Diffusion coefficient $D=(1) \times$ standard model value. (c) Diffusion coefficient $D=(0.29 / 0.30) \times$ standard model value. (d) Diffusion coefficient $D=$ $(0.28 / 0.30) \times$ standard model value. (e) Diffusion coefficient $D=(0.23 / 0.30) \times$ standard model value.

If only one climate parameter is varied at a time, the range of interest is limited by the sudden retreat of the ice sheets [as in Fig. 5 (a)]. Another common sensitivity test (Coakley, 1979; Warren and Schneider, 1979) is to vary two or more parameters simultaneously so that their basic effects partially cancel each other and the mean ice sheet position can be held "on scale". Three examples of this are shown in Fig. 6. In curves (a) and (b) large variations in $D$ are compensated by changes in the albedo contrast to maintain nearly the same temperature field for a given orbit and ice sheet size. In curves (c) a low value of the seasonal heat capacity $C$ (which produces larger seasonal cycles and higher summer temperatures at high latitudes) is compensated crudely by reducing the ablation rate by a constant factor.

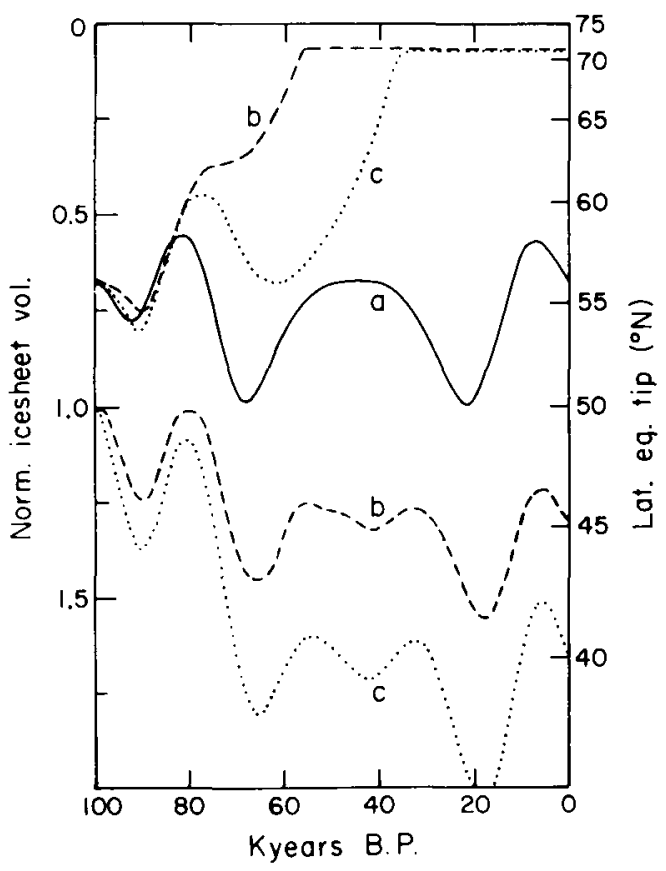

Fig. 6. Ice age curves for the standard model except: (a) Solid curve: Diffusion coefficient $D=(0.23 / 0.30) \times$ standard model value, and $a_{f}=a_{f}^{(s)}+0.017, a_{c}=$ $a_{c}^{(s)}-0.14$, where $a_{f}^{(s)}$ and $a_{c}^{(s)}$ are the standard model albedos for snow-ice/free and snow-ice/covered surfaces respectively. (b) Dashed curves: Diffusion coefficient $D$ $=(0.37 / 0.30) \times$ standard model value, and $a_{f}=a_{f}^{(s)}$ $-0.015, a_{c}=a_{c}^{(s)}+0.134$, showing two different choices of initial ice sheet size. (c) Dotted curves: Seasonal heat capacity $C=(7 / 11) \times$ standard model value, and with ablation rates (2) reduced by a factor 0.42 , showing two different choices of initial ice sheet size.

For the large value of $D$ and the low value of $C$, two different initial ice sheet sizes are chosen to show that the lower branch of stable ice sheet tip positions has shifted south to $\sim 40^{\circ}$ to $45^{\circ} \mathrm{N}$ latitude. This is because both these parameter variations favor the net snow budget of large ice sheets relative to small ones, due to increased ice sheet albedo feedback for large $D$ and due to larger summer temperature increases at higher latitudes for low $C$. Consequently the stable points " $S$ " in the corresponding orbital-curve diagrams (not shown) are located $\sim 10^{\circ}$ to $15^{\circ}$ further south than in Fig. 4. This is the only real difference in Fig. 6 from the standard model response, and the amplitude and phase of the ice sheet oscillations have remained basically the same.

We have not repeated the exercise in Fig. 6 for 
all possible combinations of parameter variations lof which there are on the order of $10^{5}$, as noted by Imbrie and Imbrie (1980)|. In the development of this model we experimented relatively unsystematically with many (perhaps $\sim 200$ ) combinations of parameter values that appear in eqs. (1) to (5), and never found any types of ice age response other than those described in this paper.

The constants in the ablation parameterization (2) are not tightly constrained by present glacial data (Pollard, 1980). We ran several ice age curves (not shown) using widely different values; for instance $(a, b, c)=(20,0,80)$ respectively so that ablation depended only on temperature, and $(a, b, c)$ $=(5,0.32,-68)$ so that the temperature dependence was half that of the standard model. In these runs, the responses to the orbital perturbations were basically unchanged from the standard model, producing secondary oscillations of the same phase and magnitude without any suggestion of full glacial-interglacial cycles. [The temperature dependence in (2) cannot be eliminated completely. With $a=0$, the model yields unrealistic seasonal cycles with snow-free high latitudes in summer and perennial snow in mid-latitudes, due to the latitudinal forms of the precipitation rate and the seasonal insolation forcing. In the present model, ablation and seasonal snow cover must be controlled mainly by temperature.]

Henderson-Sellers and Meadows (1979) and Cogley (1979) have suggested that variations of high-latitude ice cover have affected the planetary albedo to a much lesser degree than in many other models. Correspondingly Fig. 7 (a) shows a run with no albedo feedback at all, neither from the seasonal snow nor from the ice sheets; $a$ is simply a constant function of latitude. The present-day solution with this parameterization still fits the present data as well as the standard model in Section 2.3. The ice age response in Fig. 7 (a) is basically unchanged from that of the standard model, suggesting that ice-albedo feedback is not a significant mechanism for the secondary oscillations of the ice age records. Fig. 7 (b) shows another run using an albedo partly dependent on solar zenith angle, as investigated by Lian and Cess (1977). Again there was no basic change in the ice age response, as might be expected from the indifference of Fig. 7 (a) to the albedo parameterization.

Fig. 7 (c) shows an ice age run for an annual

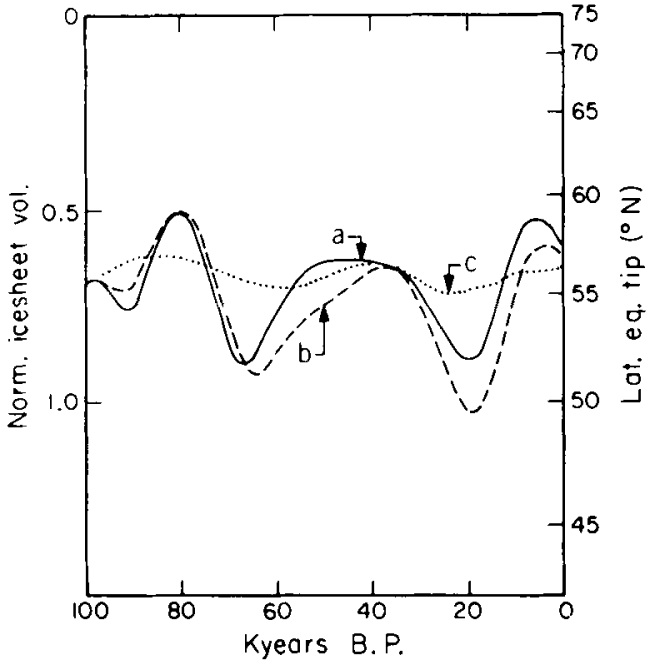

Fig. 7. Ice age curves for the standard model except: (a) Solid curve: Using fixed albedos. $a=0.35+0.2\left[\left(3 x^{2}-\right.\right.$ 1)/2] always. (b) Dashed curve: Using fraction of hourly insolation absorbed by the earth-atmosphere system $=$ $f\{0.35 \cos (s)+0.479\}$, where $s$ is hourly solar zenith angle and $f=1$ or 0.6 for snow/ice-free or snow/icecovered surfaces respectively. (c) Dotted curve: Using annual mean insolation in eq. (1), and using $(a, b, c)=$ $(10,0,122)$ respectively in eq. (2). Also setting $S=0$ in eq. (1).

mean version of our model. For this version, the current annual mean insolation at each latitude is used for $Q$ in (1), and ablation depends only on $T$. The resulting annual mean climate solutions for individual years are much the same as in North (1975), with a sea-level snowline potentially at $\sim 70^{\circ} \mathrm{N}$ (except that for Fig. 7 (b), this latitude region is occupied by ice sheet). The peak-to-peak amplitude of the ice sheet tip response of the annual mean version is reduced to $\sim 1.5^{\circ}$ in latitude, and temperature variations at fixed latitudes are all $\$ 1^{\circ} \mathrm{C}$. Therefore we find that the seasonal cycle is necessary for our model to produce realistic secondary oscillations. We have seen that seasonal albedo feedback is not necessary for the seasonal model's ice age response [Fig. 7 (a)], so seasonal albedo feedback cannot be the important difference between the seasonal and annual mean models. The important difference seems to be due to the fact that the orbital perturbations change the seasonal cycles of temperature (at the latitudes around the ice sheet tip) much more than the annual mean temperatures. The ice sheets respond just as much 
to changes in the seasonal cycles as to the annual mean changes, due mostly to the non-linearity in the ablation parameterization (2), and so the seasonal version of the model produces a much larger ice sheet response.

We now compare the sensitivities in Fig. 7 to those of two other seasonal energy-balance models. North and Coakley's (1979) model has a seasonal snowline, a perennial "ice line" fixed to the $-10^{\circ} \mathrm{C}$ zonal and annual mean isotherm, and also contains longitudinal land-ocean asymmetry. In response to obliquity changes of $1.2^{\circ}$, their perennial ice line changes by $3^{\circ}$ in latitude for the seasonal version and $2^{\circ}$ in latitude for the annual mean version. Presumably for obliquity variations of $2.4^{\circ}$ (more representative of the actual orbital perturbations) this would imply ice line changes of $6^{\circ}$ lat. (seasonal version) and $4^{\circ}$ lat. (annual mean version). In contrast, our model ice sheet tip varies by $7^{\circ}$ lat. (seasonal version) and $\sim 1.5^{\circ}$ lat. (annual mean version) in response to the actual orbital perturbations (including precession). This points to an important difference between the two models: their ice line responds only to the mean annual temperature and so the increased response of their seasonal version is due to slight variations in the residual correlation between the seasonal cycles of albedo and insolation. However, as discussed above, our more non-linear ice sheets respond directly to variations in the seasonal cycles themselves, resulting in a greater difference in response between seasonal and annual mean versions.

Schneider and Thompson (1979) find that the sensitivity of temperature to the orbital perturbations in their seasonal climate model is decreased by $\sim 30 \%$ by using fixed (constant) albedos compared to using seasonally varying albedos. When our model is run with no ice sheets we find basically the same result as theirs, and the different result implied by Fig. 7 (a) is due to the presence of the ice sheets. The albedos in our standard model can change only in the winter months when the seasonal snowline extends equatorward beyond the ice sheet tip; during the summer months the ice sheets prevent any change in albedo and so the seasonal variation of albedo is reduced considerably (cf. discussion of Table 1).

North and Coakley (1979) and Thompson and Schneider (1979) both find that the sensitivities of their models to $1 \%$ solar constant variations are nearly the same for seasonal and annual mean versions, which at first sight contradicts the result in Fig. 7 (c). However, solar constant variations primarily affect the annual mean insolation and not the seasonal cycles, and so are a fundamentally different type of forcing from the orbital perturbations in Fig. 7. [In fact we do find (not shown) that the sensitivities to small solar constant variations of our seasonal and annual mean versions are very nearly the same, with global annual mean temperatures changing by $1.8^{\circ} \mathrm{C}$ per $1 \%$ change in solar constant.]

We now mention two other modifications to the model that were tried. In some runs, monthly zonal precipitation was parameterized as a function of sea-level temperature $T$ and $\partial T / \partial$ latitude, as opposed to the fixed precipitation of the standard model. Several similar functions were tried, for instance

$$
\begin{aligned}
& \text { Precip. }\left(\mathrm{g} \mathrm{cm}^{-2} \text { month }^{-1}\right) \\
& \left.=\max \left[4 ; \mid 10 \partial T\left({ }^{\circ} \mathrm{C}\right) / \partial \text { lat. (deg. }\right) \mid\right] \\
& \quad \exp \left[T\left({ }^{\circ} \mathrm{C}\right) / 17\right]
\end{aligned}
$$

This is a very rough fit to present seasonal zonal data in Schutz and Gates (1971-4); similar parameterizations have been investigated by Schneider and Thompson (1977). The function implies a reduction in precipitation during glacial maxima associated with lower saturation vapor pressures, which has sometimes been suggested as a significant ice age factor. However, these parameterizations produced no ice age curves significantly different from those of the standard model, suggesting that the secondary oscillations of the ice sheet records have been caused more by ablation variations than accumulation variations. Data in Yapp and Epstein (1979) and Ruddiman and Mclntyre (1979) are suggestive of important ice age precipitation variations due to changing longitudinal land-ocean temperature contrasts, but this is outside the scope of the present model.

In several runs (not shown) we crudely attempted to simulate the long-term effect of the short-term "random" weather variability, as analyzed by Hasselmann (1976) and Lemke (1977). In these runs a random term, rectangularly distributed between $\pm 10 \mathrm{~g} \mathrm{~cm}^{-2}$ year $^{-1}$ [i.e., $\pm 2 \times$ $10^{4} \mathrm{~g} \mathrm{~cm}^{-2}(2 \mathrm{Kyear})^{-1}$, was added to the mean ice sheet budget at each 2 Kyear time step. The resulting ice sheet volume curves were not significantly different from the standard model response, with no suggestion of any drastic ice sheet retreats. 


\subsection{Ice sheet parameter variations}

No really different ice age responses in either the amplitude or the phase of the secondary oscillations have been produced by the climate parameter variations above. As shown below, parameter variations concerning the ice sheet can have somewhat greater effects.

Fig. 8 show ice age runs with the precipitation on all ice sheet surfaces reduced by a factor $\exp [-h(\mathrm{~km}) / 3]$ from the zonal mean, where $h$ is the local ice sheet elevation given by (4). To balance this, ablation is also reduced slightly. This crudely models the topographic blocking of storms carrying precipitation to the ice sheet interiors, as observed on Antarctica and Greenland today (Mock, 1967; Chorlton and Lister, 1968). The effect of slight variations in the weather parameters in Fig. 8 is similar to Fig. 5, but now there is no sudden transition to an ice-sheet-free northern hemisphere, and stable mean ice sheet tip positions can exist between $\sim 55^{\circ} \mathrm{N}$ and the Arctic shoreline. The corresponding orbital-curve diagram is shown in Fig. 9; these curves do not bend back to negative regimes for small ice sheets nearly so much as in Fig. 4, allowing small stable ice sheets. This also implies that ice age runs with different initial ice sheet sizes converge to the same curve, as shown by the dashed curve in Fig. 8; the equivalent curve in Fig. 3 (b) retreated to the Arctic shoreline.

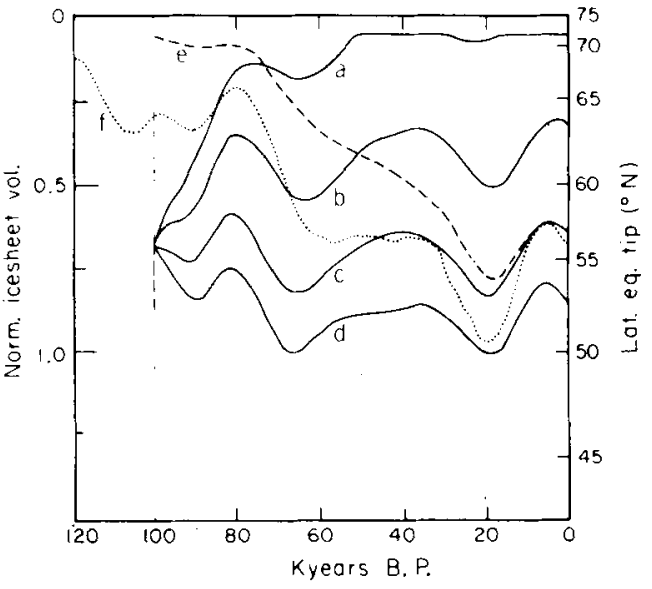

Fig. 8. Ice age curves for the standard model except that precipitation on ice sheets is reduced by factor $\exp [-h(\mathrm{~km}) / 3]$ from the zonal mean, and: (a) Ablation coefficient $b=0.30$ in eq. (2). (b) Ablation coefficient $b=0.28$ in eq. (2). (c) Ablation coefficient $b=0.26$ in eq. (2). (d) Ablation coefficient $b=0.24$ in eq. (2). (e) Dashed curve is as for curve (c) but with different initial ice sheet size. (f) Dotted curve is for standard model except that precipitation on ice sheets is altered by factor $2 \exp [-h(\mathrm{~km}) / 3]$ from the zonal mean.

The change from Fig. 4 to Fig. 9 can be explained as follows: the reduction in precipitation is greater for large ice sheets than for small ones, whereas the ablation reduction we have used to

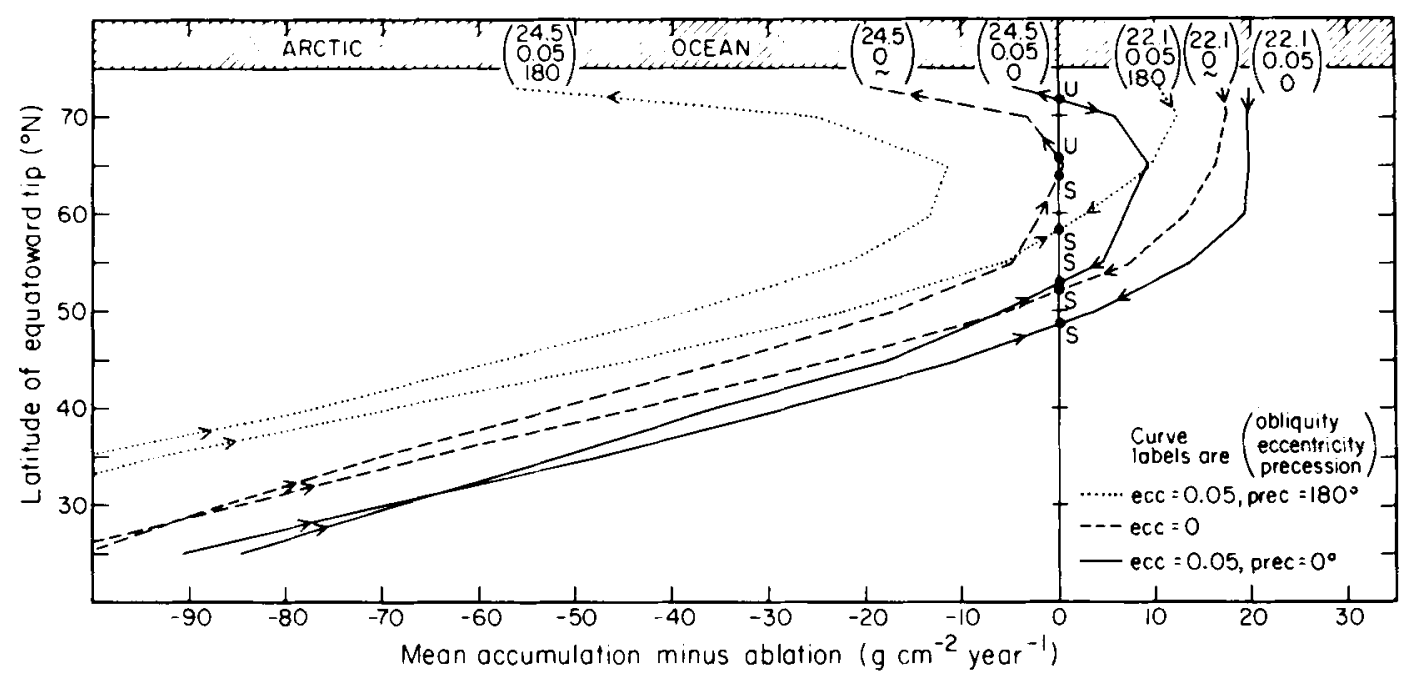

Fig. 9. As Fig. 4 except that precipitation on ice sheets is reduced by factor exp $[-h(\mathrm{~km}) / 3]$ from the zonal mean, and $b=0.26$ in eq. (2).

Tellus $32(1980), 4$ 
balance these reductions affects all ice sheet sizes equally. Any equivalent modification to the model, that favors the net snow budget of small ice sheets relative to large ice sheets, produces changes in the same direction as Fig. 9; for instance, smaller lapse rate magnitudes than $|6.5|^{\circ} \mathrm{C} \mathrm{km}^{-1}$ in (2), thinner ice sheet profiles, or less ice sheet albedo feedback. (The trend in the opposite direction was described briefly in connection with Fig. 6.)

In contrast to the precipitation reductions in ice sheet interiors, the steep flanks of ice sheets can locally increase precipitation on the sides facing the prevailing winds (Mock, 1967). To crudely test this effect we ran some ice age curves (not shown) with precipitation on all ice sheet surfaces increased by a factor of 2 over the zonal mean (and with ablation similarly increased by a constant factor). However, the only effect on the response was the predictable one of doubling the peak-to-peak amplitude of the secondary oscillations to $\sim 15^{\circ}$ in latitude. There were still no suggestions of a realistic glacial-interglacial cycle.

The amplitude of the response can also be increased by using thinner ice sheets, i.e. by reducing the value of $\lambda$ in eq. (3) below 10 meters. Fig. 10 shows two runs using $\lambda \approx 4$ meters, which lies slightly below the range of values appropriate for existing ice bodies (Paterson, 1972, table 2). Perhaps more unrealistically, isostatic depression of the land surface beneath the ice sheet is ignored. These curves show transitions between a mean ice sheet position around $\sim 55^{\circ} \mathrm{N}$ (from 300 to 200 and from 100 to $0 \mathrm{Kyears}$ BP), and a much smaller mean position trapped near the Arctic shoreline (from 200 to 100 Kyears BP). This type of response is intermediate between those in Figs. 5 and 8; now the increased amplitude of the basic oscillations (forced by obliquity and precession) is sufficient to ocassionally bridge the gap between the two stable positions. This new situation might be classified as "almost intransitive" (Lorenz, 1970).

We have chosen slightly different minimum ice sheet sizes for the two curves in Fig. 10, and this difference can occasionally be important in allowing an "escape" from the Arctic shoreline or not (e.g., at $\sim 150$ Kyears BP). In reality regional land topography becomes important for these nascent ice sheets (Loewe, 1971; Barry et al., 1975), and the present model just suggests that such details for small ice sheets can sometimes affect the form of the subsequent response.

The curves in Fig. 10 are notably similar to many of the curves produced by the ice sheet models of Weertman (1976) and Birchfield and Weertman (1978), and also to the curve produced by Calder's (1974) response equation. The ice sheet thicknesses used by Birchfield and Weertman $(\lambda=$ 14 meters) are more similar to our standard model value, and considerably greater than those in Fig. 10. Presumably this is compensated by our climate model producing smaller net snow budget variations (due to the orbital forcing) than those produced by their more geometrical parameterization; the curve in Weertman (1976), Fig. 6) that is most similar to our standard model curve [Fig. 3 (b)I uses accumulation and ablation values that are generally $\sim 1 / 2$ to $\sim 1 / 3$ of those in our model. As in their studies, we have also tried using circular

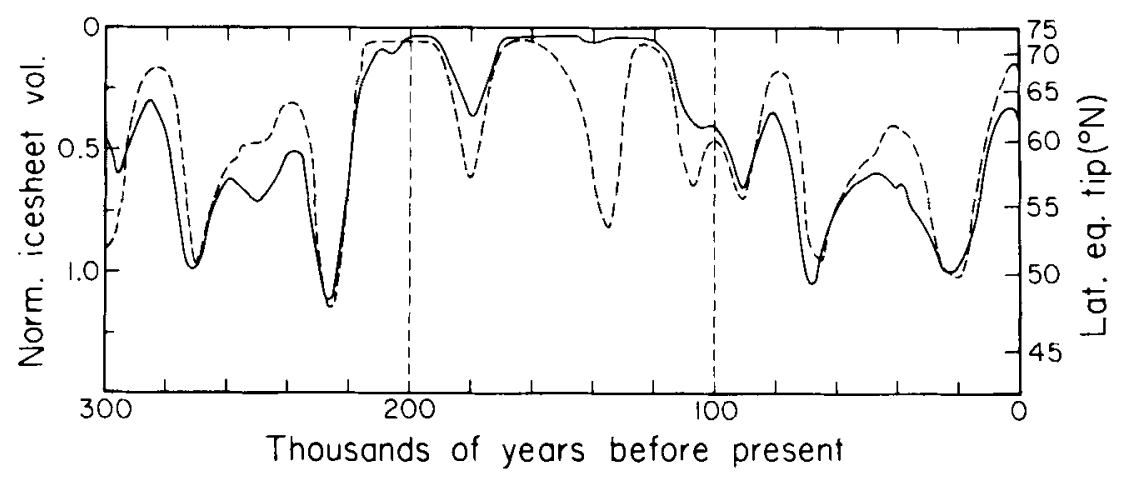

Fig. 10. Ice age curves for standard model except with no isostatic depression below the ice sheets, and: (a) Solid curve: $\lambda=4.2$ meters in eq. (3), and values of $(a, b, c)$ in eq. (2) are $(8,0.234,-39.2)$ respectively. Also minimum ice sheet half-width $=1.5^{\circ}$ lat. (b) Dashed curve: $\lambda=3.6$ meters in eq. (3), and values of $(a, b, c)$ in eq. (2) are $(8,0.226,-39.2)$ respectively. Minimum ice sheet half-width $=2.0^{\circ}$ lat. 
rather than linear northern hemispheric ice sheets, and have taken the ice sheet budget over the whole surface and not just the southern half. However these modifications leave our ice age runs basically unchanged. Although their curves and those in Fig. 10 might be considered suggestive of possible longer-period cycles and their spectra may contain some power at periods $\gtrsim 100$ Kyears (Birchfield and Weertman, 1978), the models still fail to produce realistic glacial-interglacial cycles. In fact, the "secondary" oscillations in Fig. 10 are much larger than those observed in the records.

\section{Concluding section}

In the various ice age runs above, the amplitudes of the northern hemispheric ice sheet volume fluctuations are generally between $20 \%$ to $50 \%$ of the maximum glacial volume, corresponding to between $\sim 4^{\circ}$ and $10^{\circ}$ in the latitude of its equatorward tip. These fluctuations generally agree both in phase and amplitude with the secondary oscillations of $\delta^{18} \mathrm{O}$ deep-sea core records, at least to within the small variations from record to record and within the mixed effects of ice sheet volume and ocean temperature in the $\delta^{18} \mathrm{O}$ signal (Emiliani and Shackleton, 1974).

The components of the model that are necessary to produce this response are the explicit treatment of ice sheet topography and snow budget, and the seasonal and latitudinal variations of temperature. In fact, given these features we cannot find any reasonable parameter changes that do not give realistic secondary oscillations (except for cases giving an ice-sheet-free northern hemisphere). Using annual mean insolation in (1) reduces the ice age response by a factor of $\sim 4$, but eliminating albedo feedback has very little effect on the model's response (see Fig. 7). However, albedo feedback of the ice sheets might still be important for full glacial-interglacial cycles. These sensitivities are related to the ice sheet and ablation parameterizations, as discussed in connection with Fig. 7.

We have not been able to produce realistic glacial-interglacial cycles with the present model. Starting at small ice sheet size, the model can plausibly simulate the relatively slow $\sim 80$ Kyear growths to glacial maximum [for instance by adjusting the ice sheet precipitation parameterization as in Fig. 8 (f)]; it is the drastic $\sim 20$ Kyear retreats back to interglacials that the model lacks. The estimates of Laurentide ice sheet volumes in Paterson (1972) imply mean ice sheet budgets averaging $\sim 50 \mathrm{~g} \mathrm{~cm}^{-2} \mathrm{yr}^{-1}$ between 14 and 9 Kyears BP. (Ice sheet retreat after this point was probably accelerated strongly due to being split by marine waters of Hudson Bay at $\sim 8$ Kyears BP.) In our model ice age runs the mean northern ice sheet budget varies only between $\sim+20$ and $-20 \mathrm{~g}$ $\mathrm{cm}^{-2} \mathrm{yr}^{-1}$, and this range is fairly independent of model ice sheet details (for instance, the full ice sheet retreat from 20 to 0 Kyears BP is achieved artificially in Fig. 10 by reducing the ice sheet volume inertia, but the mean ice sheet budget in this period is still $\sim-20 \mathrm{~g} \mathrm{~cm}^{-2} \mathrm{yr}^{-1}$ ). What can change in the ice sheet environment to produce mean budgets of around $-50 \mathrm{~g} \mathrm{~cm}^{-2} \mathrm{yr}^{-1}$ between 14 and 9 Kyears BP, and also produce generally positive budgets for the same ice sheet sizes at times during the previous $\sim 80$ Kyears? (cf. Andrews, 1973).

It may be that the seasonal climate part of our model is too simplified. Additional non-linearities due to land-ocean longitudinal asymmetries, realistic atmospheric/oceanic dynamics and structure, day-night cycles, cloudiness and precipitation variations, etc., could possibly alter the model response to the orbital changes to occasionally give net northern ice sheet budgets of $-50 \mathrm{~g}$ $\mathrm{cm}^{-2} \mathrm{yr}^{-1}$ (e.g., between 14 and 9 Kyears BP), without increasing the amplitude of the intervening secondary oscillations of this paper. This possibility could perhaps best be tested by a higher powered GCM, although Hartmann and Short (1979) and North and Coakley (1979) have shown how longitudinal asymmetry can be included efficiently in simple climate models. Also Cess and Wronka (1979) suggest several new short-term feedbacks that could make simple climate model response more non-linear.

Alternatively, our seasonal climate model may be basically correct, and there may be other long-term processes in the system (apart from ice sheet volume inertia) with time scales of several Kyears or longer, as proposed by Eriksson (1968), Rooth et al. (1978) and others. These processes could result in the ice sheet budget depending not only on the current ice sheet size but also on its past sizes in the previous several Kyears, and so could distinguish between the positive and negative $\left(-50 \mathrm{~g} \mathrm{~cm}^{-2} \mathrm{yr}^{-1}\right)$ budgets at the same ice sheet size, as discussed above. Specific long-term pro- 
cesses with this property include time-dependent lithospheric depression and/or non-plastic ice sheet flow (Emiliani and Geiss, 1957; Tanner, 1965), sudden jumps in the profiles of northern hemispheric and/or Antarctic ice sheets due to basal melting or sea incursions (Hollin, 1962; Wilson, 1964; Hughes, 1977; Thomas and Bentley, 1978), and deep ocean temperatures (Newell, 1974; Lemke, 1977: Saltzman, 1977). The inclusion of two or more long-term processes can produce free internal oscillations (e.g., Sergin, 1979), and it may be that such an oscillation is important for the full glacial-interglacial cycles.

Two other mechanisms related to the rapid ice sheet retreats are a possible layer of ice sheet meltwater covering a substantial part of the oceans (Adam, 1975; Berger et al., 1977; Emiliani et al., 1978), and extensive pro-glacial lakes causing calving at the feet of retreating ice sheets (Andrews, 1973). Processes such as these are not really long-term but through them the amount of ablation in one year can influence the ice sheet budgets in several succeeding years. This could cause a climatic flip-flop whereby once large ice sheets start to retreat, the oceanic meltwater layer and/or proglacial lakes increase and accelerate the retreat in succeeding years.

Before closing, we briefly discuss the relationship between Saltzman's (1977) approach and the present model. Saltzman shows that the dominant balance in the long-term global energy equation must be between three terms: global net radiation to or from space $N$, latent heat of fusion associated with the changing ice sheet mass $F$, and thermal energy of the global ( $\sim$ deep) oceans $W$. Newell (1974) has described a specific ice age mechanism involving these three quantities, and Mason (1976) has emphasized the similarity in order of magnitude between ice age variations of $F$ and the variation of
$N$ (at mid and high latitudes) caused directly by the orbital perturbations. In our model we neglect $W$, and our standard method of solution also neglects $F$, so that $N=0$ and global and annual mean energy is exactly conserved in eq. (1). Therefore, all long-term energy residuals (which are generally much smaller than the seasonal energy terms) are neglected in eq. (1), and the long-term changes are parameterized by other exploratory equations. This method decreases the computer run-time considerably and has allowed a more extensive exploration of diagnostic snow and ice sheet parameterizations. However, during periods of rapid ice sheet retreat the average rate of release of ice sheet latent heat of fusion may be $\sim 1 / 3$ that of the insolation anomaly at mid and high latitudes due to the orbital perturbations (Mason, 1976), and so $F$ should perhaps be included in eq. (1). We did include $F$ in (1) for one run over the last 100 Kyears and found it caused very little difference in the response la nearly constant $2^{\circ}$ lat. equatorward shift from the solid curve in Fig. 3(b)l. This suggests that the "direct" effects of the orbital perturbations on the ice sheet budget (via the seasonal climate) are much larger than any "adjustments" required to satisfy the long-term energy equation, at least for the secondary oscillations.

Relatively simple models such as the present one are suitable for experimenting with ice age runs incorporating the various mechanisms mentioned above. The long-term energy residuals $(N, F$, and $W$ above) can be explicitly incorporated in the model, but are not necessarily important for some mechanisms. If any mechanism is found that gives realistic glacial-interglacial cycles, the individual components and interactions could then be tested economically by higher powered GCMs (e.g., Gates, 1976a,b) and ice sheet models (e.g., Jenssen, 1977).

\section{REFERENCES}

Adam, D. P. 1975. Ice ages and the thermal equilibrium of the Earth, II. Quat. Res. 5, 161-171.

Andrews, J. T. 1973. The Wisconsin Laurentide ice sheet: dispersal centers, problems of rates of retreat, and climatic implications. Arctic and Alpine Res. 5, 185-199.

Andrews, J. T. 1975. Glacial systems. North Scituate, Mass.: Duxbury Press, 191 pp.
Barry, R. G., Andrews, J. T. and Mahaffy, M. A. 1975. Continental ice sheets: conditions for growth. Science 190, 979-981.

Beckinsale, R. P. 1973. Climatic change: a critique of modern theories. In Climate in review (ed. G. McBoyle). Boston: Houghton Mifflin, 132-151.

Berger, A. L. 1976. Obliquity and precession for the last 5,000,000 years. Astron. and Astrophys. 51, 127-135. 
Berger, A. L. 1978. Long-term variations of caloric insolation resulting from the Earth's orbital elements. Quat. Res. 9, 139-167.

Berger, W. H., Johnson, R. F. and Killingley, J. S. 1977. 'Unmixing' of the deep-sea record and the deglacial meltwater spike. Nature 269, 661-663.

Birchfield, G. E. 1977. A study of the stability of a model continental ice sheet subject to periodic variations in heat input. J. Geophys. Res. 82, $4909-4913$.

Birchfield, G. E. and Weertman, J. 1978. A note on the spectral response of a model continental ice sheet. $J$. Geophys. Res. 83, 4123-4125.

Broecker, W. S. and Van Donk, J. 1970. Insolation changes, ice volumes and the $\mathrm{O}^{18}$ record in deep-sea cores. Rev. Geophys. and Space Phys. 8, 169-198.

Budyko, M. I. and Vasishcheva, M. A. 1971. Effect of astronomical factors on Quaternary glaciations (in Russian). Meteorologija i Gidrologija 6, 37-47.

Calder, N. 1974. Arithmetic of ice ages. Nature 252, 216-218.

Cess, R. D. and Wronka, J. C. 1979. Ice ages and the Milankovitch theory: a study of interactive climate feedback mechanisms. Tellus 31, 185-192.

Chorlton, J. C. and Lister, H. 1968. Snow accumulation over Antarctica. I.A.S.H. 86, 254-263.

CLIMAP Project Members. 1976, The surface of the ice-age Earth. Science 191, 1131-1137.

Coakley, Jr., J. A. 1979. A study of climate sensitivity using a simple energy balance model. J. Atmos. Sci. 36, 260-269.

Cogley, J. G. 1979. Albedo constrast and glaciation due to continental drift. Nature 279, 712-713.

Dickson, R. R. and Posey, J. 1967. Maps of snow-cover probability for the northern hemisphere. Mon. Weath. Rev. 95, 347-353.

Emiliani, C. 1978. The cause of the ice ages. Earth and Planet. Sci. Lett. 37, 349-354.

Emiliani, C. and Geiss, J. 1957. On glaciations and their causes. Geologische Rundschau 46, 576-601.

Emiliani, C., Rooth, C. and Stipp, J. J. 1978. The late Wisconsin flood into the Gulf of Mexico. Earth and Planet. Sci. Lett. 41, 159-162.

Emiliani, C. and Shackleton, N. J. 1974. The Brunhes epoch: isotopic paleo-temperatures and geochronology. Science '93, 511-514.

Eriksson, E. 1968. Air-ocean-icecap interactions in relation to climatic fluctuations and glaciation cycles. Met. Monog. 8, 68-92.

Evans, D. L. and Freeland, H. J. 1977. Variations in the Earth's orbit: pacemaker of the ice ages? Science 198, 528-530.

Flint, R. F. 1971. Glacial and Quaternary geology. New York: J. Wiley, $892 \mathrm{pp}$.

Gates, W. L. 1976a. Modeling the ice-age climate. Science 191, 1138-1144.

Gates, W. L. 1976b. The numerical simulation of ice-ageclimate with a global general circulation model. $J$. Atmos. Sci. 33, 1844-1873.

Hantel, M. 1972. Polar boundary conditions in zonally averaged global climate models. J. Appl. Meteor. 13, 752-759.

Hartjenstein, G. and Efger, J. 1979. Linear parameterization of large-scale eddy transports. Tellus 31 , 89-101.

Hartmann, D. L. and Short, D. A. 1979. On the role of zonal asymmetries in climate change. J. Atmos. Sci. $36,519-528$.

Hasselmann, K. 1976. Stochastic climate models. Part 1. Theory. Tellus 28, 473-485.

Hays, J. D., Imbrie, J. and Shackleton, N. J. 1976. Variations in the Earth's orbit: pacemaker of the ice ages. Science 194, 1121-1132.

Henderson-Sellers, A. and Meadows, A. J. 1979. The zonal and global albedos of the Earth. Tellus 31, $170-173$.

Hollin, J. T. 1962. On the glacial history of Antarctica. J. Glaciol. 4, 173-195.

Hughes, T. 1977. West Antarctic ice streams. Rev. Geoph. and Space Phys. 15, 1-46.

Hunkins, K., Be, A. W. H., Opdyke, N. D. and Mathieu, G. 1971. The late Cenozoic history of the Arctic Ocean. In Late Cenozoic glacial ages (ed. K. K. Turekian). New Haven, Conn.: Yale Univ. Press, 215-238.

Imbrie, J. and Imbrie, K. P. 1979. Ice ages: solving the mystery. Short Hills, New Jersey: Enslow Publ., 224 pp.

Imbrie, J. and Imbrie, J. Z. 1980. Modelling the climatic response to orbital variations. Science, 207, 943953.

Jenssen, D. 1977. A three-dimensional polar ice-sheet model. J. Glaciol. 18, 373-389.

Kominz, M. A. and Pisias, N. G. 1979. Pleistocene climate: deterministic or stochastic? Science 204, $171-172$.

$\mathrm{Ku}, \mathrm{T}$. and Broecker, W. S. 1967. Rates of sedimentation in the Arctic Ocean. Prog. Oceanogr. 4, 95-104.

Kukla, G. J. 1975. Missing link between Milankovitch and climate. Nature 253,600-603.

Lemke, P. 1977. Stochastic climate models, part 3. Application to zonally averaged energy models. Tellus 29, 385-392.

Lian, M. S. and Cess, R. D. 1977. Energy balance climate models: a reappraisal of ice-albedo feedback. J. Atmos. Sci. 34, 1058-1062.

Loewe, F. 1971. Considerations on the origin of the Quaternary icesheet of North America. Arctic and Alpine Res. 3, 331-344.

Lorenz, E. N. 1970. Climatic change as a mathematical problem. J. Appl. Meteor. 9, 325-329.

Lorenz, E. N. 1979. Forced and free variations of weather and climate. J. Atmos. Sci. 36, 1367-1376.

Mason, B. J. 1976. Towards the understanding and prediction of climatic variations. Quart. J. Roy. Met. Soc. 102, 473-498.

Meier, M. F. 1960. Distribution and variations of glaciers in the United States exclusive of Alaska. I.A.S.H. 54, $420-429$. 
Milankovitch, M. 1941. Canon of insolation and the ice age problem. Belgrade: Royal Serbian Academy, Special Publication 133, $482 \mathrm{pp}$. Translated by Israel Program for Scientific Translation, Jerusalem, 1969.

Mock, S. J. 1967. Calculated patterns of accumulation on the Greenland ice sheet. J. Glaciol. 6, 795-803.

Newell, R. E. 1974. Changes in the poleward energy flux by the atmosphere and ocean as a possible cause for ice-ages. Quat. Res. 4, 117-127.

North, G. R. 1975. Theory of energy-balance climate models. J. Atmos. Sci. 32, 2033-2043.

North, G. R. and Coakley, Jr., J. A. 1979. Differences between seasonal and mean annual energy balance model calculations of climate and climate sensitivity. J. Atmos. Sci. 36, 1189-1204.

Paschinger, V. 1912. Die schneegrenze in verschiedenen klimaten. Peterm. Georg. Mitt Erganz. 37, 93 pp.

Paterson, W. S. B. 1969. The physics of glaciers. Oxford: Pergamon Press, $250 \mathrm{pp}$.

Paterson, W. S. B. 1972. Laurentide icesheet: estimated volumes during late Wisconsin. Rev. Geophys. and Space Phys. 10,885-917.

Pollard, D. 1978. An investigation of the astronomical theory of the ice ages using a simple climate-icesheet model. Nature 272, 233-235.

Pollard, D. 1980. A simple parameterization for ice sheet ablation rate. Tellus 32, 384-388.

Rooth, C. G. H., Emiliani, C. and Poor, H. W. 1978. Climate response to astronomical forcing. Earth and Planet. Sci. Letl. 41, 387-394.

Ruddiman, W. F. and McIntyre, A. 1979. Warmth of the subpolar north Atlantic Ocean during northern hemispheric ice-sheet growth. Science 204, 173-175.

Saltzman, B. 1977. Global mass and energy requirements for glacial oscillations and their implications for mean ocean temperature oscillations. Tellus 29, $205-212$.

Saltzman, B. and Vernekar, A. D. 1971. Note on the effect of Earth orbital radiation variations on climate. J. Geophys. Res, 76, 4195-4197.

Saltzman, B. and Vernekar, A. D. 1975. A solution for the northern hemispheric climatic zonation during a glacial maximum. Quat. Res. 5, 307-320.

Schneider, S. H. and Thompson, S. L. 1977. A surface temperature parameterization for zonal precipitation. EOS 58, 1144.

Schneider, S. H. and Thompson, S. L. 1979. Ice ages and orbital variations: some simple theory and modeling. Quat. Res. 12, 188-203.

Schuster, R. L. 1954. Project Mint Julep, part III. U.S. Army Snow Ice and Permafrost Res. Est. Rep. 19, 10 pp.

Schutz, C. and Gates, W. L. 1971 to 1974. Global climatic data R-915 (1971), R-915/1 (1972), R-1029 (1972), R-915/2 (1973), R-1317 (1973), R-1029/1 (1974), R-1425 (1974). A.R.P.A., Rand Corp., Santa Monica, Calif.
Sergin, V. Ya. 1979. Numerical modeling of the glaciers-ocean-atmosphere global system. J. Geophys. Res. 84, 3191-3204.

Shackleton, N. J., 1969. The last interglacial in the marine and terrestrial records. Proc. Roy. Soc. London Ser. B. 174, 135-154.

Shaw, D. M. and Donn, W. L. 1968. Milankovitch radiation variations: a quantitative evaluation. Science $162,1270-1272$.

Suarez, M. 1976. An evaluation of the astronomical theory of the ice ages. Ph.D. Thesis, Princeton Univ., $108 \mathrm{pp}$.

Suarez, M. J. and Held, I. M. 1976. Modelling climatic response to orbital parameter variations. Nature, 263 , 46-47.

Suarez, M. J. and Held, I. M, 1979. The sensitivity of an energy balance climate model to variations in the orbital parameters. J. Geophys. Res. 84, 4825-4836.

Sugden, D. E. and John, B. S. 1976. Glaciers and Landscape. New York: J. Wiley, $376 \mathrm{pp.}$

Tanner, W. F. 1965. Cause and development of an ice age. J. Geol. 73, 413-430.

Thomas, R. H. and Bentley, C. R. 1978. A model for Holocene retreat of the West Antarctic ice sheet. Quat. Res. 10, 150-170.

Thompson, S. L. and Schneider, S. H. 1979. A seasonal zonal energy balance climate model with an interactive lower layer. J. Geophys. Res. 84, 24012414.

Van Loon, H. 1979. The association between latitudinal temperature gradient and eddy transport. Part 1: Transport of sensible heat in winter. Mon. Weath. Rev. 107, 525-534.

van Woerkom, A. J. J. 1953. The astronomical theory of climate changes. In Climatic change-evidence, causes and effects (ed. H. Shapley). Cambridge, Mass.: Harvard Univ. Press, 147-157.

Vernekar, A. D. 1972. Long-period global variations of incoming solar radiation. Met. Monog. 12, 1-20.

Warren, S. G. and Schneider, S. H. 1979. Seasonal simulation as a test for uncertainties in the parameterizations of a Budyko-Sellers climate model. $J$. Atmos. Sci. 36, 1377-1391.

Weertman, J. 1961. Stability of ice-age icesheets. $J$. Geophys. Res. 66, 3783-3792.

Weertman, J. 1964. Rate of growth or shrinkage of nonequilibrium icesheets. J. Glaciol. 5, 145-158.

Weertman, J. 1976. Milankovitch solar radiation variations and ice age ice sheet sizes. Nature 261, 17-20.

White, G. H. 1976. Climatic feedbacks calculated from satellite observations. G.F.D. Summer Study Program, Woods Hole Oceanog. Inst., 168-190.

Williams, J. H. 1974. Simulation of the atmospheric circulation using the NCAR global circulation model with present day and glacial period boundary conditions. Ph.D. Thesis, Univ. of Colorado, Boulder, 328 pp. 
Williams, L. D. 1978. Ice-sheet initiation and climatic influences of expanded snow cover in Arctic Canada. Quart. Res. 10, 141-149.

Wilson, A. T. 1964. Origin of ice ages: an ice shelf theory for Pleistocene glaciation. Nature 201, 147-149.
Yapp, C. J. and Epstein, S. 1977. Climatic implications of $\mathrm{D} / \mathrm{H}$ ratios of meteoric water over North America (9500-22,000 B.P.) as inferred from ancient wood cellulose $\mathrm{C}-\mathrm{H}$ hydrogen. Earth and Planet. Sci. Lett. 34, 333-350.

\section{РЕАКЦИЯ ЗОНАЛЬНОЙ КЛИМАТИЧЕСКОЙ МОДЕЛИ С ЛЕДНИКОВЫМИ ЩИТАМИ НА ОРБИТАЛЬНЫЕ ВОЗМУЩЕНИЯ В ТЕЧЕНИЕ ЧЕТВЕРТИЧНЫХ ЛЕДНИКОВЫХ ПЕРИОДОВ}

При помощи простой климатической модели, явно описывающей ледниковые шиты, исследуется астрономическая теория ледниковых периодов. Одноуровенкая зонально осредненная сезонная энергобалансовая модель решается численно с определением температуры на уровне моря как функции широты и месяца (подобно Норсу, 1975). Снеговой покров, меняющийся с сезоном (что влияет на планетарное альбедо) включен диагностически путем простых параметризаций ежемесячных выпадений и таяний снега. Полные годовые накопления и абляция на поверхности ледниковых щитов на каждой широте вычисляются с теми же параметризациями, что и для снега (c температурой, учитывающей высоту щита при вертикальном градиенте $-6,5^{\circ} \mathrm{C} \mathrm{kм}^{-1}$ ). Рассмотрение ледниковых шитов следует Уиртману (1976), где течение льда аппроксимируется как течение идеально пластичной жидкости, что ограничивает профиль шита параболой. Ледяной щит северного полушария простирается к экватору от $75^{\circ} \mathrm{c}$.II. (что соответствует береговой линии Северного ледовитого океана).
Модельные кривые для последних 100 тыс.лет рассчитаны вычислениями годичной нпогодын, как описано выше, для каждых 2 тыс.лет с инсоляцией, взятой с учетом реальных возмушенй параметров земной орбиты. Изменения в размерах ледникового шита для каждого шага в 2 тыс.лет зависят только от ежегодного баланса снега, проинтегрированного по всей поверхности щита. В этих расчетах южная граница ледяного щита северного полушария колеблется в пределах $7^{\circ}$ широты, что правильно моделирует фазы и приблизительные амплитуды высокоуастотных компонент (43 и 22 тыс.лет) данных глубоководных осадков (Хэйс и др., 1976). Однако модель неспособна воспроизвести основные ледниковые циклы (От 100 до 120 тыс.лет) этих цанных. Описана чувствительность модельных расчетов к изменениям различных ее параметров, но ни одно из этих изменений не улучшает сушественно сходимости расчетных крнвых к упомянутым данным. В заключение мы обсуждаем типы механизмов, которые могли бы дать реалистические ледниковые циклы. 